\title{
Investigating the Influence of Different Process Parameters on Shrinkage of Injection-Molded Parts
}

\author{
A.R. Jafarian and M. Shakeri \\ Faculty of Engineering, Mazandaran University, Shariati Ave. PO Box 484, Babol, Iran
}

\begin{abstract}
Different models have been proposed to investigate the effects of various process parameters on shrinkage of plastic parts, which in most cases the effect of each parameter is obtained by changing one factor at a time. In this research, a simple flat model has been used and a simulation code has been developed. Then, through this simulation code, the effects of different process parameters have been investigated. This code was run for a typical thermoplastic (polycarbonate) and finally, a Design Of Experiments (DOE) approach was used to study the effects of multiple variables on shrinkage simultaneously.
\end{abstract}

Key words: Computer-aided Engineering (CAE), Injection Molding, Shrinkage, Residual Stress, Design of Experiments (DOE)

\section{INTRODUCTION}

Injection molding process is one of the most important polymer processing methods for fabrication of plastic parts. During this process, the polymer experiences a complex deformation and temperature history that affects the final product. The demands on high dimensional accuracy and quality of the product require knowledge of the mechanisms that influence the properties of the product such as shrinkage. This quality item is the subject of this work in which it (shrinkage) has been simulated considering residual stresses. In this regard, a simulation program has been developed as a part of CAE in injection molding.

Residual stress is one of the main causes of shrinkage and warpage in plastic parts and is produced due to high pressure, temperature change and relaxation of polymer chains. Different researches have been carried out to estimate residual stresses and investigate its effects.

Choi and Im [1] calculated residual stresses for amorphous thermoplastics in a flat shape based on a thermo-rheologically simple viscoelastic material model. To determine the effects of additional material supply during the packing stage, the reference strain approach was used. This approach derived from a model introduced by Bushko and Stokes [2]. Based on this approach, that initially introduced by Santhanam [3], the general constitutive equation must be expressed with respect to initial cavity dimensions at any instant instead of stress free state of the material. This approach also requires that the phase of the material (solid or liquid) in each layer be definite at any instant. In fact, amorphous thermoplastics do not exhibit a sharp transition between the liquid and solid states and therefore, a transition criterion is required to specify their phase. Such a criterion defined by Bushko and Stokes. They introduced a new material parameter titled as critical relaxation time and expressed that a material is a liquid when its characteristic relaxation time is less than a critical relaxation time. Using a linear thermoviscoelastic model, Kabanemi and Crochet [4] predicted residual stresses and dimensional changes in several parts, but the packing pressure effects were not studied. Liu [5] simulated residual stress and warpage using a visco-elastic phase transformation model and assumed a standard linear solid for the solidified polymer and a viscous fluid model for the polymer melt. Kabanemi et al. [6] developed a numerical simulation code for predicting residual stresses and residual deformations that arise in the post-packing stage. They used both elastic and viscoelastic models for their calculations and compared the results with each other. Zoetelief et al. [7] investigated the effect of the holding stage of the injection molding process on the thermal residual stress distribution using a linear viscoelastic model and compared this with experimental results. LeGrand [8] used a simple two-term tensile relaxation function above glass transition temperature, $\mathrm{T}_{\mathrm{g}}$, and constant elastic modulus below $\mathrm{T}_{\mathrm{g}}$ to calculate transient stresses in injection molded parts. In his research, the effects of packing pressure were not investigated.

Huang and Tai [9] used the experimental design of Taguchi method to determine warpage of a thin shell part, using the commercial software C-Mold. They could get the optimum combination of process parameters to produce plastic parts with minimum warpage. Chang [10] applied Taguchi method to investigate the effects of process conditions on the shrinkage of High-Density Polyethylene (HDPE), General-Purpose Polystyrene (GPS) and Acrylonitrile Butadiene-Styrene (ABS) and the optimal conditions predicted by Taguchi method were experimentally verified. 
In this study, the model from Choi and Im [1] was used to investigate the effects of different process parameters on shrinkage and residual stresses of a flat part. Flow effects were neglected and material was assumed to be thermo-rheologically simple viscoelastic above $T_{g}$ and elastic below $T_{g}$. The reference strain approach [3] was used to determine the effects of additional material supply during the packing stage. Considering these assumptions, a simulation code is developed and then the results are achieved for a sample amorphous polymer.

Finally, to assess the percentage influence of each factor on shrinkage, considering simultaneous change of different factors, the procedure of ANOVA in Taguchi approach is employed.

Material Model: In this study, a flat model was used and flow effects were neglected. Therefore, only the packing and cooling stages of injection molding were considered for investigation. Heat transfer was assumed to be one-dimensional and temperature gradients in planar directions ( $\mathrm{x}$ and $\mathrm{y}$ ) were ignored.

Thermorheologically simple behavior requires that all molecular changes be affected by temperature in the same way and as a result, only amorphous thermoplastics may exhibit such behavior and this property cannot be assigned to crystalline structures [2]. Therefore, the model under investigation can only cover polymers with amorphous structures.

Equilibrium Equations: Due to symmetry and lack of heat transfer in planar directions, in the absence of body forces, equilibrium equations are only functions of independent variable, $\mathrm{z}$. Therefore,

$$
\frac{\partial \tau_{\mathrm{xz}}(\mathrm{z}, \mathrm{t})}{\partial \mathrm{z}}=0, \frac{\partial \tau_{\mathrm{yz}}(\mathrm{z}, \mathrm{t})}{\partial \mathrm{z}}=0, \frac{\partial \sigma_{\mathrm{z}}(\mathrm{z}, \mathrm{t})}{\partial \mathrm{z}}=0
$$

which have the general solution as follows:

$$
\tau_{\mathrm{xz}}=\tau_{\mathrm{xz}}(\mathrm{t}) ; \tau_{\mathrm{yz}}=\tau_{\mathrm{yz}}(\mathrm{t}) ; \sigma_{\mathrm{z}}=\mathrm{q}(\mathrm{t})
$$

The results show that the three stress components, $\tau_{\mathrm{xz}}$, $\tau_{\mathrm{yz}}$ and $\sigma_{\mathrm{z}}$, are constant through the thickness at any instant and can be estimated from their values at the boundaries which equal 0, 0 and $q(t)$, respectively. Due to symmetry and lack of the planar heat transfer, another shear stress component, $\tau_{\mathrm{xy}}$, will also equal zero.

Constitutive Equation: Material behavior is assumed to be thermorheologically simple viscoelastic. In order to assess polymer relaxation data in different temperatures, the concept of time-temperature equivalence is used. With this condition, the linear constitutive equation will be in the following form: $\sigma(t)=\int_{0}^{t} L\left\{\xi(t)-\xi\left(t^{\prime}\right)\right\} \cdot d\left[\varepsilon\left(t^{\prime}\right)-\theta\left(t^{\prime}\right)\right]$

where, $\mathrm{L}(\mathrm{t}), \xi$ and $\theta$ are material relaxation modulus, material time and thermal strain, respectively. The material time or pseudotime, $\xi$, is a new time scale which is related to time, $t$, as follows:

$$
\xi(\mathrm{t})=\int_{0}^{\mathrm{t}} \phi\left\{\mathrm{T}\left(\mathrm{t}^{\prime}\right)\right\} \cdot \mathrm{d} \mathrm{t}^{\prime}
$$

where, $\phi$ is a shift function which shows the amount of horizontal shift of relaxation curves with respect to a master curve obtained in a reference temperature. In general, this parameter can be computed using the socalled Williams-Landel-Ferry (WLF) equation [11], which is given by

$$
\log \phi=\frac{\mathrm{C}_{1} \cdot\left(\mathrm{T}-\mathrm{T}_{\mathrm{ref}}\right)}{\mathrm{C}_{2}+\left(\mathrm{T}-\mathrm{T}_{\mathrm{ref}}\right)}
$$

where, $\mathrm{C}_{1}$ and $\mathrm{C}_{2}$ are material dependent constants. The equation for thermal strain, $\theta$, can be written as:

$$
\theta(\mathrm{t})=\int_{\mathrm{T}_{0}}^{\mathrm{T}(\mathrm{t})} \alpha\left\{\mathrm{p}, \mathrm{T}^{\prime}\right\} \cdot \mathrm{dT}^{\prime}
$$

where, $\alpha$ is the coefficient of thermal expansion of the material.

The material relaxation modulus, $\mathrm{L}(\mathrm{t})$, can be expressed through the following relation

$$
\mathrm{L}(\mathrm{t})=\sum_{\alpha=1}^{\mathrm{M}} \mathrm{A}^{(\alpha)} \mathrm{L}^{(\alpha)}(\mathrm{t})
$$

Where, $L^{(\alpha)}(t)$ are different components of matrix $L(t)$. These functions express different relaxation data for a polymer. The value of $\mathrm{M}$ and constant matrices, $\mathrm{A}^{(\alpha)}$ depend on the class of materials under consideration. $\mathrm{M}$ equals 2 and 6 for an isotropic and orthotropic material, respectively. The matrices $A^{(\alpha)}$ can be written for an isotropic material as follows:

$$
\mathrm{A}^{(1)}=\frac{2}{3}\left[\begin{array}{ccc}
2 & -1 & -1 \\
-1 & 2 & -1 \\
-1 & -1 & 2
\end{array}\right], \mathrm{A}^{(2)}=\left[\begin{array}{lll}
1 & 1 & 1 \\
1 & 1 & 1 \\
1 & 1 & 1
\end{array}\right]
$$

$\mathrm{L}^{(1)}(\mathrm{t})=\mathrm{G}(\mathrm{t}), \mathrm{L}^{(2)}(\mathrm{t})=\mathrm{K}(\mathrm{t})$

Where, $G(t)$ and $K(t)$ are shear and bulk relaxation modulus and calculated using:

$$
\begin{aligned}
& \mathrm{G}(\mathrm{t})=\sum_{\beta=1}^{\mathrm{m}} \mathrm{c}^{\beta} \cdot \mathrm{e}^{-\mathrm{t} / \tau^{\beta}} \\
& \mathrm{K}(\mathrm{t})=\mathrm{K}_{0}
\end{aligned}
$$

In these equations $c^{\beta}$ are constant values and $\tau^{\beta}$ are different relaxation times of the material. Moreover, the 
bulk relaxation modulus was assumed to be constant. Finally, the linear constitutive equation, Eq. 3, can be rewritten as follows:

$$
\begin{aligned}
& \sigma(\mathrm{t})=\sum_{\alpha=1}^{\mathrm{M}} \mathrm{A}^{(\alpha)} \cdot \mathrm{L}^{(\alpha)}(\mathrm{t}) \cdot[\varepsilon(\mathrm{t})-\theta(\mathrm{t})]^{\text {isotropic }}= \\
& {\left[\mathrm{A}^{(1)} \cdot \mathrm{G}(\mathrm{t})+\mathrm{A}^{(2)} \cdot \mathrm{K}(\mathrm{t})\right] \cdot \mathrm{e}(\mathrm{t})}
\end{aligned}
$$

Reference Strain: After filling the cavity with plastic melt, the packing pressure is applied to compensate for part shrinkage in the mold by adding molten material to the free space created in the cavity. This pressure can be applied until complete solidification of the material in the mold. To investigate packing pressure effects, the general constitutive equation 10 , cannot be used, because the strain field in this equation was stated with respect to stress free state of the material and the additional material supply during packing stage was not considered in this equation. The reference strain concept was used by Santhanam to overcome this problem. Based on this concept, the local strain in constitutive equation must be expressed with respect to an initial strain at each time-step. This initial strain is specified for each material layer as it undergoes a liquid to solid transition and after solidification, the value of this parameter will be constant. In other words, its value does not change in solid layers while increasing in liquid layers.

The following relation represents the modified form of constitutive equation, considering reference strain:

$$
\begin{aligned}
& \sigma(t)=\sum_{\alpha=1}^{M} A^{(\alpha)} \cdot L^{(\alpha)}(t) \cdot\left[\varepsilon(t)-\left(\theta(t)+\varepsilon_{r}(t)\right)\right]^{\text {isotropic }} \\
& =\left[A^{(1)} \cdot G(t)+A^{(2)} \cdot K(t)\right] \cdot e(t)
\end{aligned}
$$

$\mathrm{e}(\mathrm{t})=\varepsilon(\mathrm{t})-\theta(\mathrm{t})-\varepsilon_{\mathrm{r}}(\mathrm{t})$

where, $\varepsilon_{\mathrm{r}}$ indicates the value of initial strain which is time-dependent. In this equation, $\theta$ was replaced by $\theta+\varepsilon_{\mathrm{r}}$ to change the reference with respect to which the constitutive equation is expressed.

The strain of a melt, which is stationary and under the hydrostatic stress $\sigma=-$ pl and when changes in the specific volume is not infinitesimal, as is the case for many thermoplastics [12], is given by the following relation:

$\epsilon_{\text {melt }}=\frac{1}{3} \ln \{v(\mathrm{t}) / v(0)\} \overrightarrow{\mathrm{I}}, \quad \overrightarrow{\mathrm{I}}=\left[\begin{array}{lll}1 & 1 & 1\end{array}\right]^{\mathrm{T}}$

where, $\mathrm{v}$ is the specific volume of the material. According to Santhanam's formulation, the reference strain parameter, which is specified for each material layer at its solidification time, is only dependent on the melt pressure and calculated by:

$$
\begin{aligned}
& \in_{\mathrm{r}}(\mathrm{z})=-\epsilon_{\text {melt }}\left(\mathrm{P}_{\mathrm{s}}(\mathrm{z}), \mathrm{T}_{\mathrm{s}}(\mathrm{z})\right) \\
& =-\frac{1}{3} \ln \frac{\mathrm{v}\left(\mathrm{P}_{\mathrm{s}}(\mathrm{z}), \mathrm{T}_{\mathrm{s}}(\mathrm{z})\right)}{\mathrm{v}\left(0, \mathrm{~T}_{\mathrm{s}}(\mathrm{z})\right)} \overrightarrow{\mathrm{I}}
\end{aligned}
$$

Where, $\mathrm{P}_{\mathrm{s}}$ and $\mathrm{T}_{\mathrm{s}}$ indicate pressure and temperature at solidification time and are position-dependent.

The packing pressure effects are investigated through following assumptions:

* The material is constrained in planar directions ( $\mathrm{x}$ and $\mathrm{y}$ ).

* The packing pressure may be time-dependent: $\sigma_{\mathrm{z}}(\mathrm{t})=-\mathrm{p}(\mathrm{t})$

* The change in the material thickness will be zero before complete solidification and until cavity pressure drops to zero, $\mathrm{p}(\mathrm{t})=0$.

$\Delta \mathrm{l}_{0}(\mathrm{t})=\int_{-1_{0} / 2}^{1_{0} / 2} \in{ }_{\mathrm{z}}(\mathrm{z}, \mathrm{t}) \mathrm{dz}$

* The value of reference strain is constant for solid layers while increasing in liquid layers. The following relations represent the increment of this parameter in both phases:

$\Delta \varepsilon_{\mathrm{r}}(\mathrm{z}, \mathrm{t})=\Delta \varepsilon_{\mathrm{r}} \cdot \overrightarrow{\mathrm{I}}$, for liquid layers,

$\Delta \varepsilon_{\mathrm{r}}(\mathrm{z}, \mathrm{t})=0$, for solid layers,

The increment of reference strain for different liquid layers is the same as each other. Finally, to specify the phase of the material, a liquid to solid transition criterion must be defined. The criterion proposed by Bushko and Stokes, is used here. Based on this criterion, the material is considered to be a liquid when its characteristic shear relaxation time is less than a critical relaxation time, $\tau_{\mathrm{c}}$. The characteristic shear relaxation time of a material at a given temperature is calculated by:

$$
\tau_{\mathrm{rel}}^{(1)}(\mathrm{T})=\frac{\tau_{\mathrm{ref}}^{(1)}}{\Phi(\mathrm{T})}
$$

Where, at solidification temperature it can be written as:

$$
\tau_{\mathrm{c}}=\frac{\tau_{\mathrm{ref}}^{(1)}}{\Phi\left(\mathrm{T}_{\mathrm{sol}}\right)}
$$

where, $\tau_{\text {ref }}^{(1)}$ denotes the shear relaxation time at a reference temperature, usually glass transition temperature, and $\Phi$ is the so-called WLF shift function. By using this equation, the solidification temperature for an amorphous thermoplastic can be calculated.

Compatibility Equations: The compatibility equations for nonzero strain components are as follows: 
$\frac{\partial^{2}}{\partial z^{2}} \epsilon_{x}(z, t)=0, \frac{\partial^{2}}{\partial z^{2}} \epsilon_{y}(z, t)=0$

Solving these equations results in

$$
\begin{aligned}
& \epsilon_{\mathrm{x}}=\bar{\epsilon}_{\mathrm{x}}-\mathrm{zK}_{\mathrm{y}} \\
& \epsilon_{\mathrm{y}}=\bar{\epsilon}_{\mathrm{y}}-\mathrm{zK}_{\mathrm{x}}
\end{aligned}
$$

where, $\bar{\varepsilon}_{\mathrm{x}}$ and $\bar{\varepsilon}_{\mathrm{y}}$ denote the planar strains values at mid-plane $(\mathrm{z}=0)$ and $\mathrm{K}_{\mathrm{y}}$ and $\mathrm{K}_{\mathrm{x}}$ are components of the curvature around $y$ and $x$, respectively.

Heat Transfer Equation: The one-dimensional equation of heat transfer is expressed in the following general form:

$$
\begin{aligned}
& \rho \cdot \mathrm{c} \cdot \frac{\partial \mathrm{T}(\mathrm{z}, \mathrm{t})}{\partial \mathrm{t}}=\frac{\partial}{\partial \mathrm{z}}\left[\mathrm{k} \cdot \frac{\partial \mathrm{T}(\mathrm{z}, \mathrm{t})}{\partial \mathrm{z}}\right] \\
& \left\{\begin{array}{c}
-\mathrm{k} \cdot \frac{\partial \mathrm{T}}{\partial \mathrm{z}}=\mathrm{h}_{1}\left[\mathrm{~T}-\mathrm{T}^{(1)}(\mathrm{t})\right], \mathrm{z}=-1_{0} / 2 \\
\mathrm{k} \frac{\partial \mathrm{T}}{\partial \mathrm{z}}=\mathrm{h}_{\mathrm{u}}\left[\mathrm{T}-\mathrm{T}^{(\mathrm{u})}(\mathrm{t})\right], \mathrm{z}=1_{0} / 2
\end{array}\right\}
\end{aligned}
$$

where $\rho, \mathrm{c}, \mathrm{k}$ denote density, specific heat and thermal conductivity of the material, respectively. $h_{l}$ and $h_{u}$ are heat transfer coefficients of lower and upper surfaces and $\mathrm{T}^{(\mathrm{l})}$ and $\mathrm{T}^{(\mathrm{u})}$ are corresponding temperatures.

Numerical Solution: The material is divided into $\mathrm{N}$ layers in the thickness direction, not necessarily of equal thickness. Then, both heat transfer and constitutive equations will be solved by numerical methods.

The general form of one-dimensional heat transfer equation is shown as below:

$$
\frac{\partial^{2} u}{\partial x^{2}}=\frac{c \cdot \rho}{k} \cdot \frac{\partial u}{\partial t}
$$

To solve this equation the Crank-Nicolson method was used which its general form can be written as:

$$
\begin{aligned}
& \mathrm{r}=\mathrm{k} \cdot \Delta \mathrm{t} / \mathrm{c} \cdot \rho(\Delta \mathrm{x})^{2} \\
& --------------- \\
& -r \cdot u_{i-1}^{j+1}+(2+2 r) u_{i}^{j+1}-r \cdot u_{i+1}^{j+1} \\
& =r \cdot u_{i-1}^{j}+(2-2 r) u_{i}^{j}+r \cdot u_{i+1}^{j}
\end{aligned}
$$

The numerical solution procedure for linear constitutive equation consists of two stages. In the first stage, a finite difference scheme is used to calculate the value of different parameters for each layer at one time-step and then in the second stage, a finite element method is implemented to determine the global variables at that time-step. Having performed the whole calculations at each time-step, the procedure has been continued for the next time-steps. In the following of this section, we will describe the summary of the numerical method, which has been used to find the solution.

The material relaxation data are expressed in the following form:

$$
\mathrm{L}^{(\alpha)}(\mathrm{t})=\mathrm{c}^{(\alpha, 0)}+\sum_{\beta=1}^{\mathrm{m}_{\alpha}} \mathrm{c}^{(\alpha, \beta)} \cdot \mathrm{e}^{-\mathrm{t} / \tau^{(\alpha, \beta)}}
$$

where, $c^{(\alpha, \beta)}$ and $\tau^{(\alpha, \beta)}$ are material constants and are extracted from the master curve of the polymer. The parameter $\mathrm{L}^{(\alpha)}(\mathrm{t})$ in eq. 11 will be replaced by its equivalent from eq. 19 and then eq. 11 can be written as follows:

$$
\begin{aligned}
& \sigma(t)=\sum_{\alpha=1}^{M} A^{(\alpha)} \cdot c^{(\alpha, 0)} \cdot e(t) \\
& +\sum_{\alpha=1}^{M} A^{(\alpha)} \sum_{\beta=1}^{m_{\alpha}} c^{(\alpha, \beta)} \cdot s^{(\alpha, \beta)}(t)
\end{aligned}
$$

where the vector $s^{(\alpha, \beta)}(t)$ is defined by:

$$
\begin{aligned}
& \mathrm{s}^{(\alpha, \beta)}(\mathrm{t})=\mathrm{e}^{-\mathrm{t} / \tau^{(\alpha, \beta)}} \cdot \mathrm{e}(\mathrm{t}) \\
& =\int_{0}^{\mathrm{t}} \exp \left\{-\frac{\xi(\mathrm{t})-\xi\left(\mathrm{t}^{\prime}\right)}{\tau^{(\alpha, \beta)}}\right\} \cdot \operatorname{de}\left(\mathrm{t}^{\prime}\right)
\end{aligned}
$$

while $\mathrm{e}(0)$ equals zero. To solve this equation a finite difference method is used which results in the following recurrence formula:

$$
s_{j+1}=P_{j} \cdot s_{j}+Q_{j} \cdot \Delta e_{j}
$$

Here, $P_{j}$ and $Q_{j}$ are given by:

$$
\mathrm{P}_{\mathrm{j}}=\mathrm{e}^{-\Delta \xi_{\mathrm{j}} / \tau} ; \mathrm{Q}_{\mathrm{j}}=\frac{1-\mathrm{e}^{-\Delta \xi_{\mathrm{j}} / \tau}}{\Delta \xi_{\mathrm{j}} / \tau}
$$

and from eq. 4 , the increment of material time at $\mathrm{j}^{\text {th }}$ time-step, $\Delta \xi_{\mathrm{j}}$, is written as:

$$
\Delta \xi_{\mathrm{j}}=\xi_{\mathrm{j}+1}-\xi_{\mathrm{j}}=\Phi\left(\mathrm{T}_{\mathrm{j}}\right) \cdot \Delta \mathrm{t}
$$

Considering eqs. 23 and 25, the single-layer equilibrium equation can be written by the following relation:

$$
\mathrm{k}_{\mathrm{j}} \cdot \Delta \varepsilon_{\mathrm{j}}=\Delta \sigma_{\mathrm{j}}+\mathrm{k}_{\mathrm{j}} \cdot\left(\Delta \theta_{\mathrm{j}}+\left(\Delta \varepsilon_{\mathrm{r}}\right)_{\mathrm{j}}\right)+\Delta \mathrm{g}_{\mathrm{j}}
$$




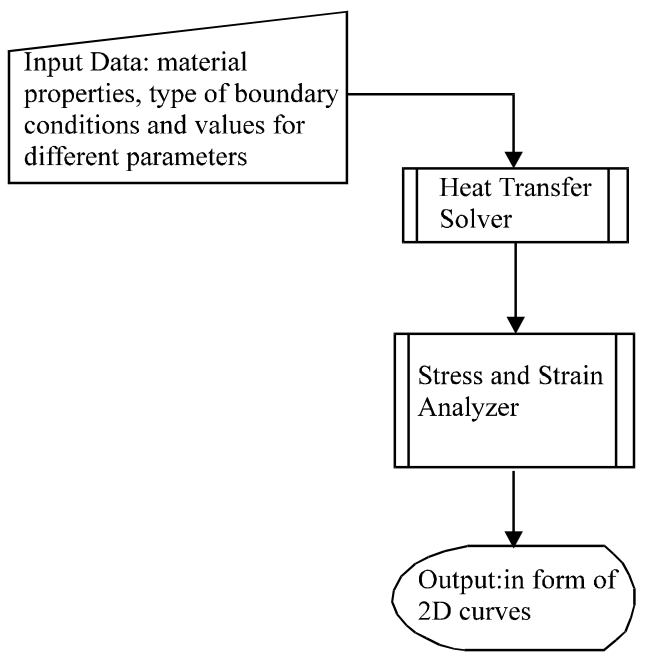

Fig. 1: General Form of Simulation Algorithm

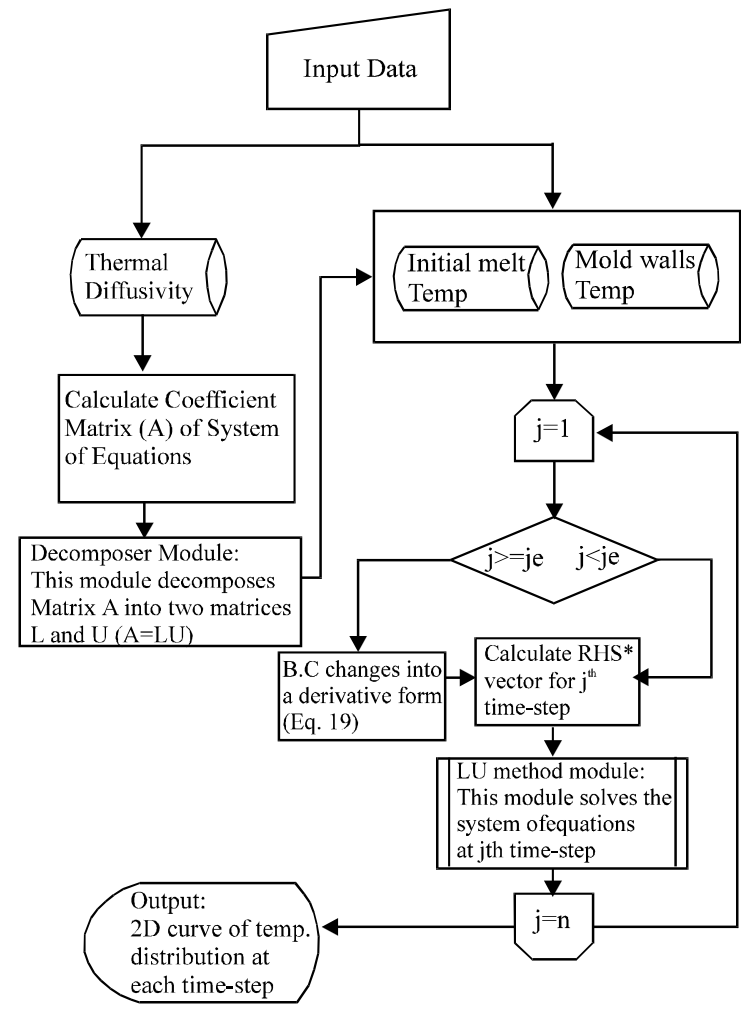

Fig. 2: Heat Transfer Solver Module

Here, the local stiffness matrix $\mathrm{k}_{\mathrm{j}}$ (LSM) and the vector $\Delta \mathrm{g}_{\mathrm{j}}$ are expressed by:

$$
\begin{aligned}
& \mathrm{k}_{\mathrm{j}}=\sum_{\alpha=1}^{\mathrm{M}} \mathrm{A}^{(\alpha)}\left\{\mathrm{c}^{(\alpha, 0)}+\sum_{\beta=1}^{\mathrm{m}_{\alpha}} \mathrm{c}^{(\alpha, \beta)} \cdot \mathrm{Q}_{\mathrm{j}}^{(\alpha, \beta)}\right\} \\
& \Delta \mathrm{g}_{\mathrm{j}}=\sum_{\alpha=1}^{\mathrm{M}} \mathrm{A}^{(\alpha)} \sum_{\beta=1}^{\mathrm{m}_{\alpha}} \mathrm{c}^{(\alpha, \beta)} \cdot\left(1-\mathrm{P}_{\mathrm{j}}^{(\alpha, \beta)}\right) \cdot \mathrm{s}_{\mathrm{j}}^{(\alpha, \beta)}
\end{aligned}
$$

Having calculated the values of different parameters-like stress and strain--for different layers at $\mathrm{j}^{\text {th }}$ timestep, a finite element method is applied. In this FEM, the planar strains $\epsilon_{\mathrm{x}}$ and $\epsilon_{\mathrm{y}}$ from eq. 25 will be replaced by their equivalents from eq. 16 and then, this single layer equation is integrated through the thickness and the following relations are obtained:

$$
\begin{aligned}
& \mathrm{K} \Delta \mathrm{x}=\Delta \mathrm{f}+\Delta \mathrm{u}-\mathrm{w} \Delta \sigma_{\mathrm{z}}+\Delta \varepsilon_{\mathrm{r}} \mathrm{V} \\
& \Delta_{0}=\mathrm{d}_{1} \Delta \sigma_{\mathrm{z}}+\Delta \mathrm{d}_{2}+\mathrm{d}_{3} \Delta \varepsilon_{\mathrm{r}}-\mathrm{w}^{\mathrm{T}} \Delta \mathrm{x}
\end{aligned}
$$

The global variables like cavity pressure, shrinkage and warpage are acquired by this equation. The relations for global stiffness matrix, $\mathrm{K}$, planar strain vector, $\Delta \mathrm{x}$, average force vector, $\Delta \mathrm{f}$, vectors $\Delta \mathrm{u}, \mathrm{w}$ and $\mathrm{v}$ and scalars $\mathrm{d}_{1}, \Delta \mathrm{d}_{2}$ and $\mathrm{d}_{3}$ can be found in [2]. Finally, the thickness shrinkage, $\Delta \mathrm{l}_{0}$, is given by:

$$
\Delta 1_{0}=\sum_{\mathrm{i}=1}^{\mathrm{N}} \Delta \varepsilon_{\mathrm{z}}^{\mathrm{i}} \cdot \Delta \mathrm{z}^{\mathrm{i}}
$$

Simulation Algorithm: The general form of the simulation algorithm is shown in Fig. 1. This algorithm contains one input box, two sub-modules and one output box. The algorithms for sub-modules, Heat Transfer Solver and Stress and Strain Analyzer, are shown in Fig. 2 and 3, respectively.

\section{Case Study}

Sample Material: Polycarbonate (PC) was selected as a sample material to run the simulation code. Shear relaxation function of $\mathrm{PC}$ at $\mathrm{T}_{\mathrm{g}}\left(155^{\circ} \mathrm{C}\right)$ is expressed by a two-term prony-series function [13] as follows:

$\mathrm{G}(\mathrm{t})[\mathrm{Mpa}]=781.075 \exp (-\mathrm{t} / 0.1)+3.95 \exp \left(-\mathrm{t} / 10^{5}\right)$

The bulk relaxation modulus is assumed to be constant with value of $3140 \mathrm{MPa}$ and the characteristic shear relaxation time, at $\mathrm{T}_{\mathrm{g}}$, is calculated using eq. 30 as follows:

$$
\begin{aligned}
\tau_{\text {ref }} & =\tau_{\text {rel }}(\mathrm{Tg}, \mathrm{p}=0)=\frac{\sum_{\beta=1}^{\mathrm{m}} \mathrm{G}^{\beta} \cdot \tau^{\beta}}{\sum_{\beta=1}^{\mathrm{m}^{\alpha}} \mathrm{G}^{\beta}} \\
\tau_{\mathrm{ref}} & =\frac{781.075 \times 0.1+3.95 \times 10^{5}}{781.075+3.95}=503 \mathrm{sec} .
\end{aligned}
$$

To assess the solidification temperature of the material, $\mathrm{T}_{\text {sol }}$, eq. 17 is used. The shift function, $\Phi$, is computed by eq. 5 in which the reference temperature corresponds to $T_{g}$. Now one can obtain the solidification temperature from eqs. 5 and 17 ,

$$
\left\{\begin{array}{c}
\log \phi(T)=\frac{C_{1} \cdot\left(T-T_{g}\right)}{C_{2}+\left(T-T_{g}\right)} \\
\tau_{c}=\frac{\tau_{\text {ref }}}{\phi\left(T_{\text {sol }}\right)}
\end{array}\right\} \Rightarrow
$$




$$
\mathrm{T}_{\text {sol }}=\mathrm{T}_{\mathrm{g}}+\frac{\mathrm{C}_{2} \cdot \log \left(\tau_{\text {ref }} / \tau_{\mathrm{c}}\right)}{\mathrm{C}_{1}-\log \left(\tau_{\text {ref }} / \tau_{\mathrm{c}}\right)}
$$

Assuming the critical relaxation time of $0.01 \mathrm{sec}, \mathrm{T}_{\mathrm{sol}}$ will equal $179^{\circ} \mathrm{C}$. The values for different process parameters are shown below:

Ejection time, $\mathrm{t}_{\mathrm{e}},=10 \mathrm{sec}$.

Initial melt temperature $=290^{\circ} \mathrm{C}$

Mold wall temperature $=80^{\circ} \mathrm{C}$

Packing pressure $=250 \mathrm{bar}$

Final temperature $=20^{\circ} \mathrm{C}$

Part thickness $=2 \mathrm{~mm}$
Parametric Results: Using input data given in the previous section, the process is simulated through which the effects of different process parameters such as critical relaxation time, melt temperature, mold temperature and packing pressure on shrinkage and residual stress will be studied. Figure 4 shows the variation of temperature distribution through thickness at different time-steps. The initial melt temperature is $290^{\circ} \mathrm{C}$, which decreases abruptly in the boundary layers. The whole material solidifies at $4.2 \mathrm{sec}$.

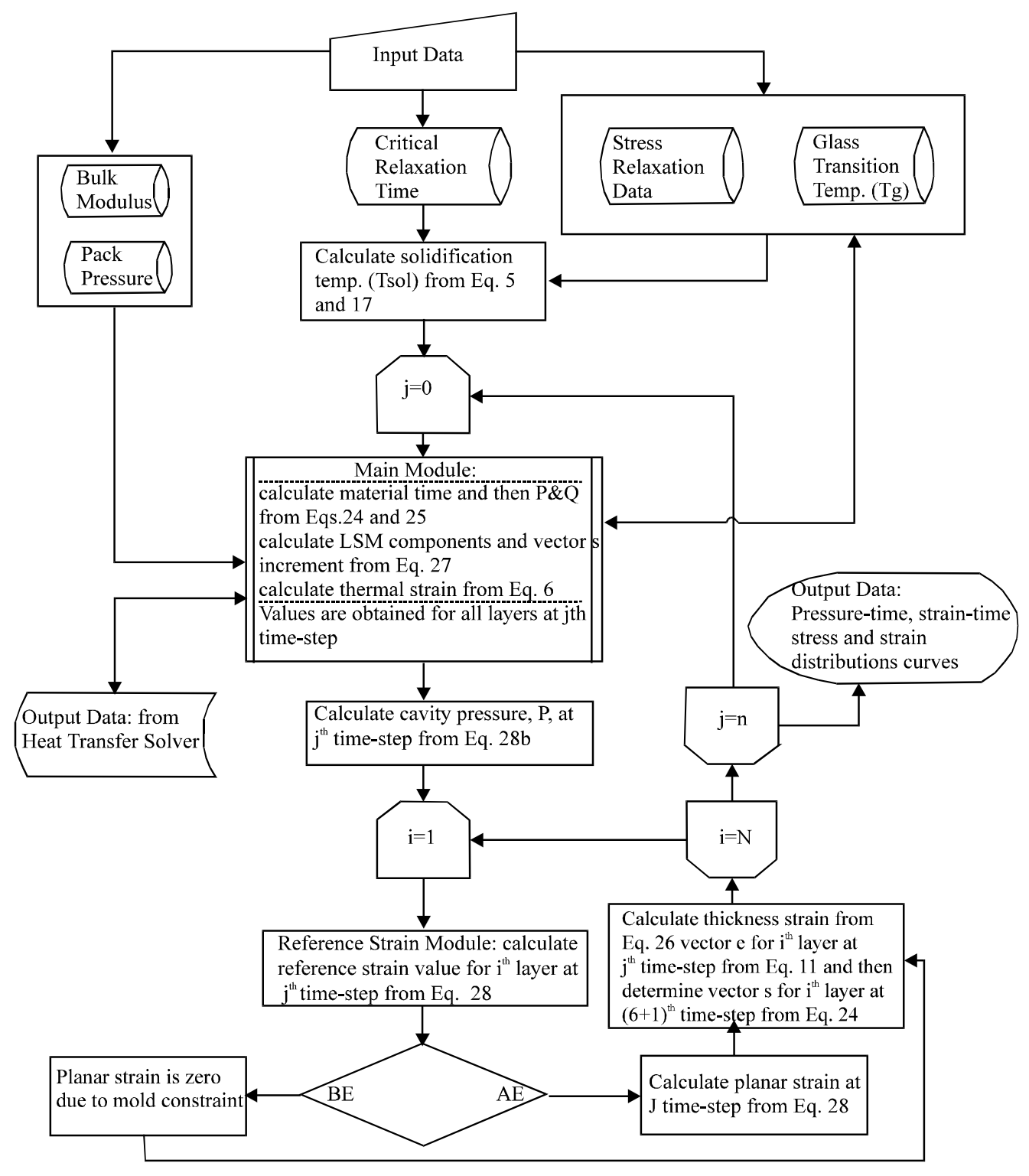

Fig. 3: Stress and Strain Analyzer Module 


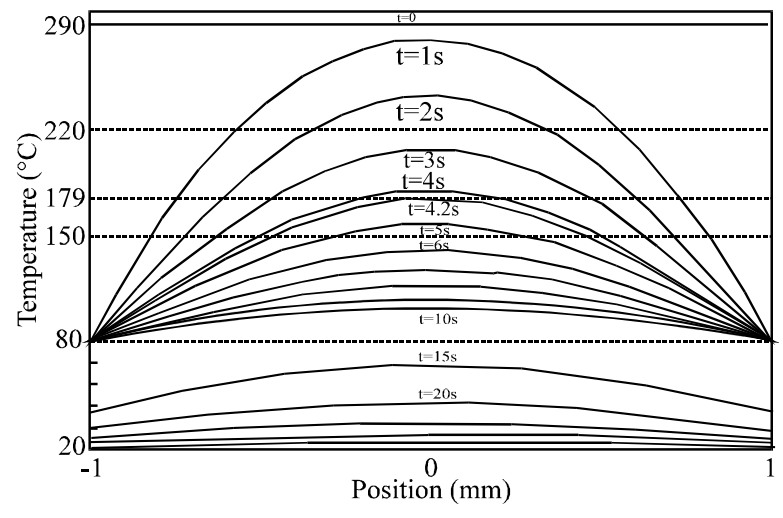

Fig. 4:Temperature Distributions through Thickness in Different Time-steps

Planar stresses, before and after ejection (BE and AE), are shown in Fig. 5a and 5b, respectively. Due to high temperature gradients, the variation of stress in side layers will be considerable, but stress is constant in the central region, which is in liquid phase. After complete solidification, the compressive stresses reduce rapidly due to reduction in the cavity pressure. At ejection time, the release of the material from planar constraint results in a sudden change in stress distribution, which can be observed in Fig. 5b. The final distribution consists of two side regions and a central region, which are termed as skin and core regions, respectively.

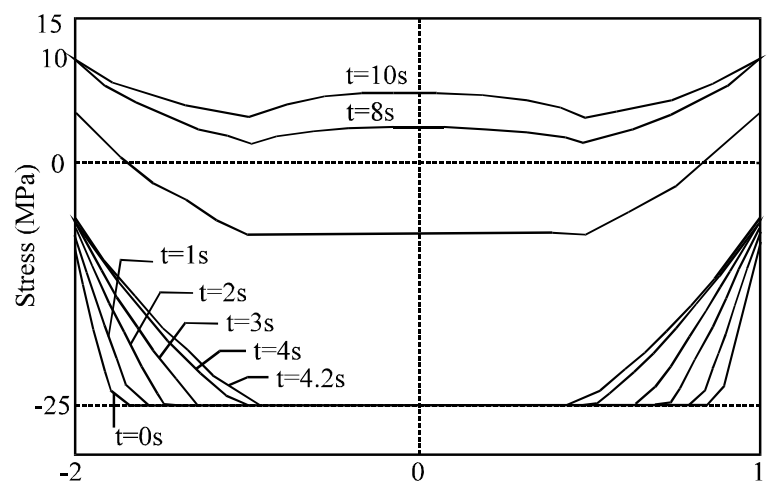

Fig. 5a: Variation of Stress Distribution in Different Time-steps BE

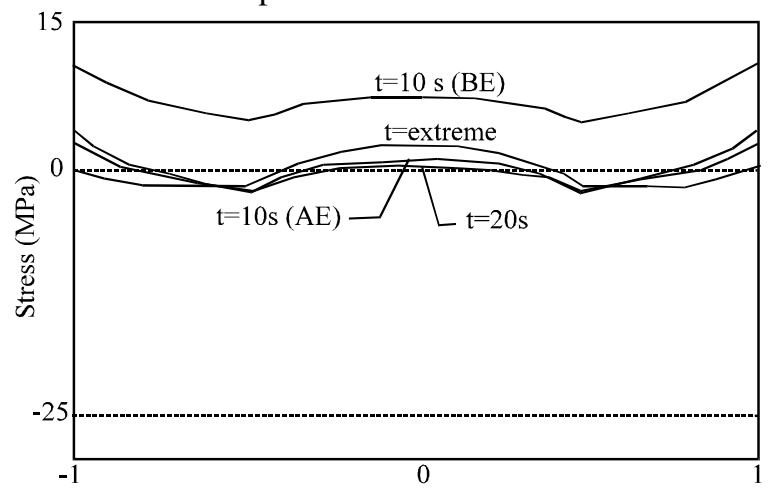

Fig. 5b: Variation of Stress Distribution in Different Time-steps AE
Figures $6 \mathrm{a}$ and $6 \mathrm{~b}$ present the evolution of thickness strain for different layers before and after ejection, respectively. These strains were obtained relative to the reference strain for each layer.

The reference strain distribution through thickness is shown in Fig. 7. As shown in the figure, the reference strain is increased in liquid layers before solidification, but its value is constant after solidification. Furthermore, the reference strain curve will have a constant shape after complete solidification time (CST), as shown in the Fig. 7 at time-step $t=4.2 \mathrm{sec}$. Also, all liquid layers have the same reference strain value at any instant.

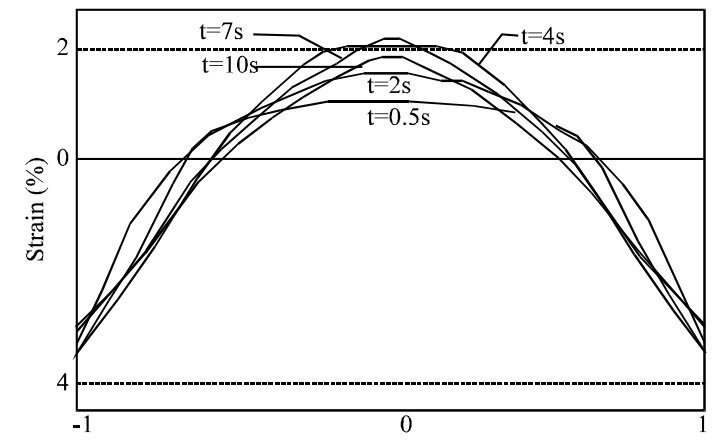

Fig. 6a: Variation of Thickness Strain distribution in Different Time-steps BE

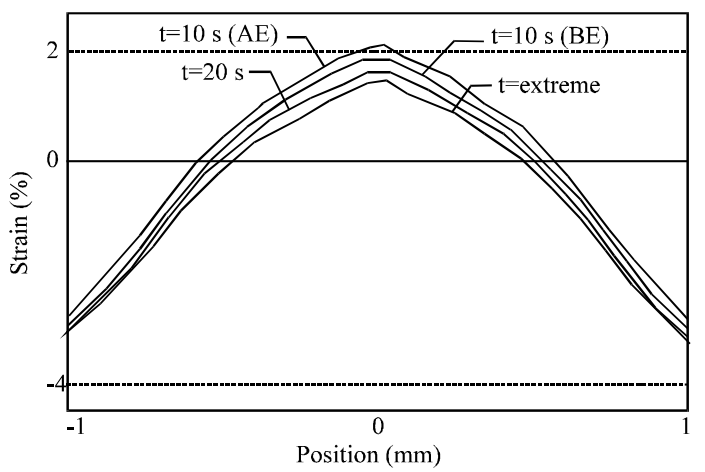

Fig. 6b: Variation of Thickness Strain Distribution in Different time-steps AE

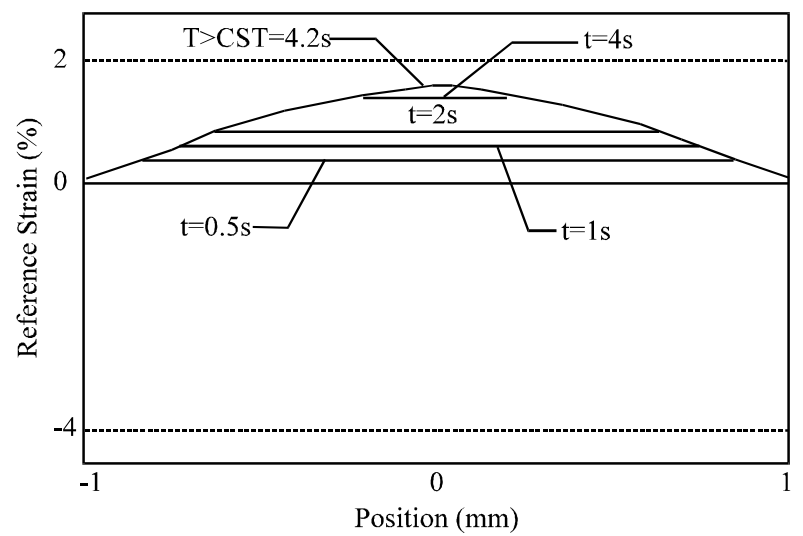

Fig. 7: Variation of Reference Strain Parameter through Thickness with Time 
Effect of critical relaxation time: Higher critical relaxation times (CRT) result in lower solidification temperatures, as represented by eq. 32 , and as a result, the core width decreases by increasing CRT. Decreasing core width corresponds to adding more material to the cavity during packing stage and leads to less shrinkage. Figure 8 shows the variations of shrinkage respect to logarithm of CRT. As shown in the figure, the effect of CRT on thickness shrinkage is more than its effect on planar shrinkage.

The effect of CRT on residual stress distribution is shown in Fig. 9. This figure presents that higher CRTs result in lower residual stresses. In fact, the complete solidification time increases with CRT and also, pressure drop occurs more slowly due to lower relaxation times. Moreover, figure 9 presents that the core width decreases by increasing CRT.

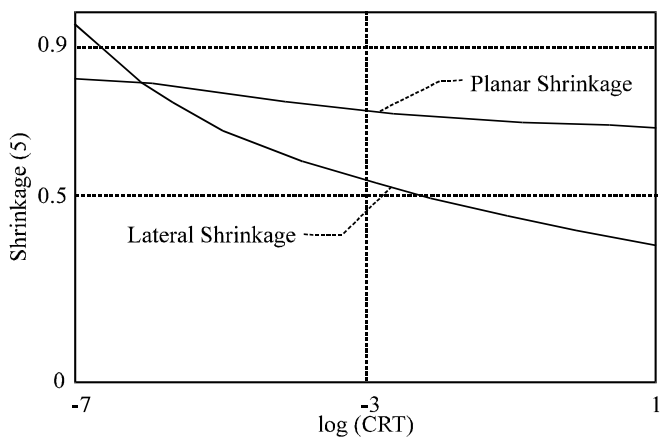

Fig. 8: Variation of Shrinkage Versus Logarithm of CRT

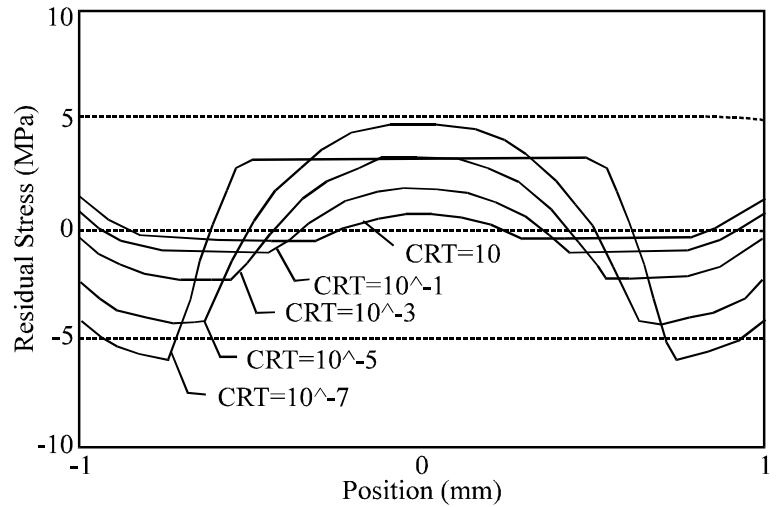

Fig. 9: Residual Stress Distribution Curves for Different CRTs

Effect of Initial Melt Temperature: Figures 10 and 11 present that the initial melt temperature has a very small effect on shrinkage and residual stresses, respectively. As a matter of fact, the core width is partially influenced by this parameter and consequently, there is a very slight change in shrinkage. Furthermore, the initial melt temperature has small effect on the rate of pressure drop and consequently on residual stress distribution as shown in Fig. 11.

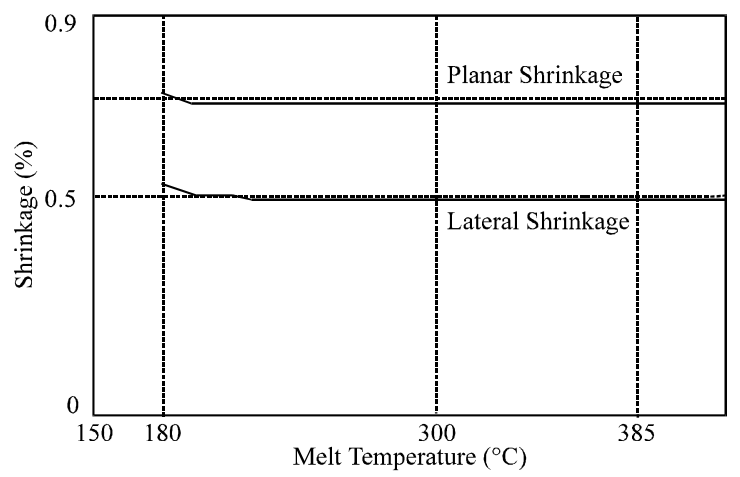

Fig. 10: Variation of Shrinkage Versus Initial Melt Temperature

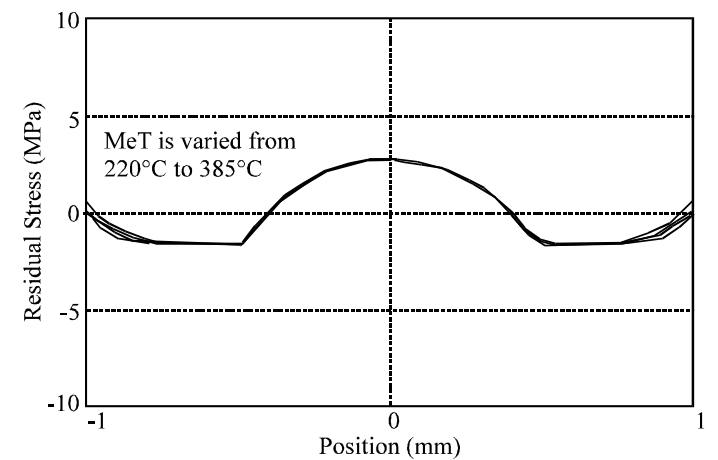

Fig. 11: Residual Stress Distribution Curves for Different Initial Melt Temperatures

Effect of Mold Temperature: The effects of mold temperature on shrinkage and residual stresses are represented by Fig. 12 and 13, respectively. Higher mold temperatures result in higher thickness shrinkage, as shown in Fig. 12. In fact, increasing mold temperature leads to higher core width and therefore, more thickness shrinkage, while there is a very slight change in planar shrinkage due to mold constraint. Moreover, when mold temperature exceeds $125^{\circ} \mathrm{C}$, layers in rubbery-solid state exist at ejection time, which results in a sudden change in both shrinkages. Figure 13 also shows that an abrupt change occurs in the distribution of residual stresses above $125^{\circ} \mathrm{C}$. At this condition, the material is ejected while rubbery solid layers with low relaxation times exist and consequently, high stresses are produced.

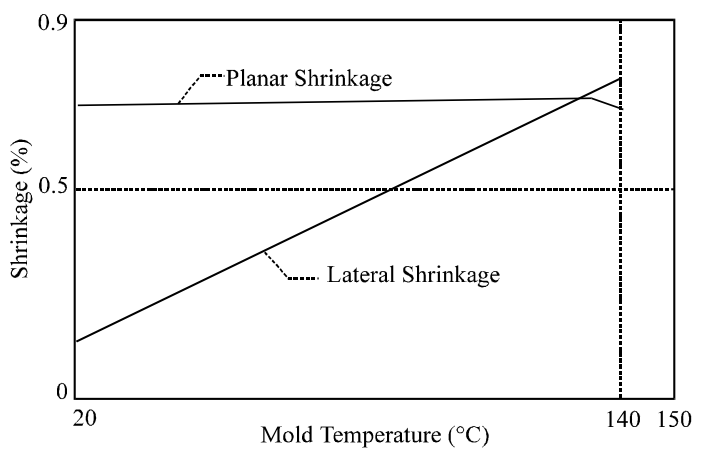

Fig. 12: Variation of Shrinkage Versus Mold Temperature 


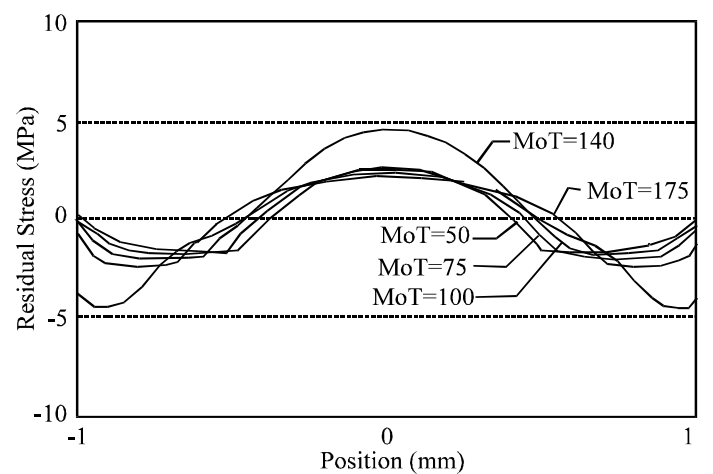

Fig. 13: Residual Stress Distribution Curves for Different Mold Temperatures

Effect of Pack Pressure: Figure 14 shows the variation of shrinkage with respect to packing pressure. Packing pressure changes both shrinkages in large scale, as shown in the figure. More material will be added to the cavity with increasing packing pressure and as a result material shrinks less.

The effect of packing pressure on residual stress distribution is shown in Fig. 15. This figure presents that higher packing pressures result in higher residual stresses. Residual stress distribution has no change when cavity pressure drops to zero after complete glass transition time (CGT $=5.8 \mathrm{sec})$, because of the fact that the rates of pressure drop in these cases are the same until CGT, as shown in Fig. 16. In this figure, vertical line corresponds to CGT.

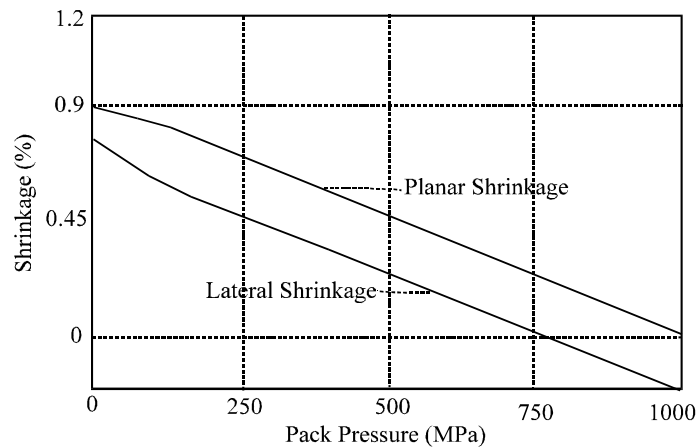

Fig. 14: Variation of Shrinkage Versus Packing Pressure

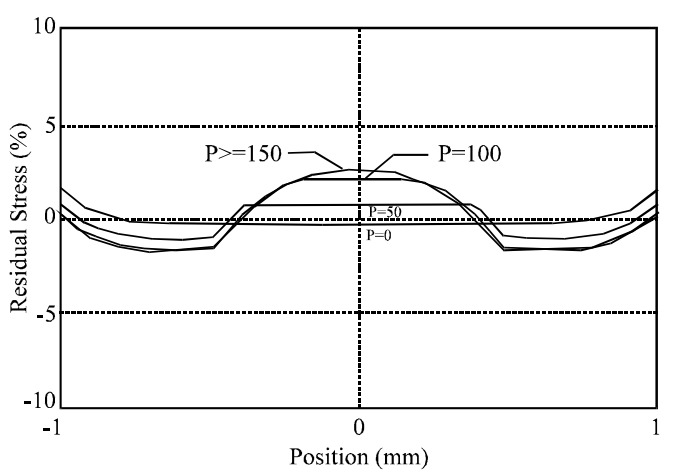

Fig. 15: Residual Stress Distribution curves for Different Packing Pressures

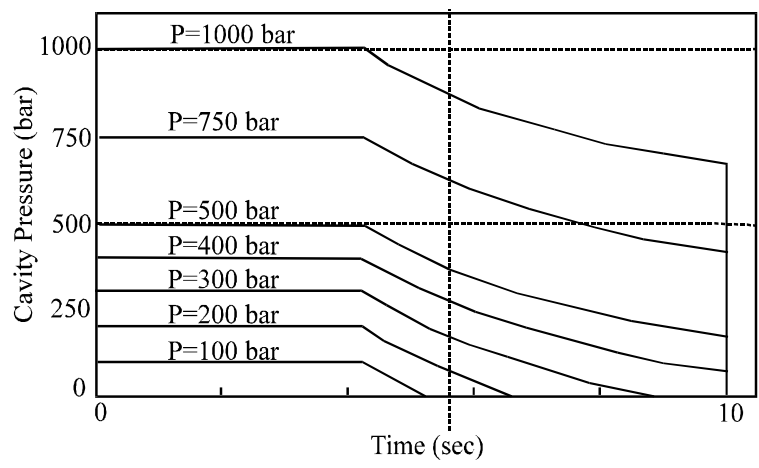

Fig. 16: Variation of Cavity Pressure Versus Time for Different Pack Pressures

Effect of Gate Freezing: The effects of packing pressure is investigated on condition that the gate freezes before complete solidification time (CST) and gate solidification time is assumed to be 3 seconds $\left(t_{\text {fre }}\right.$ $=3 \mathrm{sec}$.).

When gate freezing occurs before CST, the molten material cannot be added to compensate for shrinkage. In this case, shrinkage will increase compared to a fully packed material. Figure 17 shows the variation of shrinkage respect to packing pressure in a partially packed material.

The distributions of residual stresses for different packing pressures, while gate freezing occurs, are shown in Fig. 18. The residual stresses increase with packing pressure until pressure drops to zero after CGT, which is the same as fully packed condition.

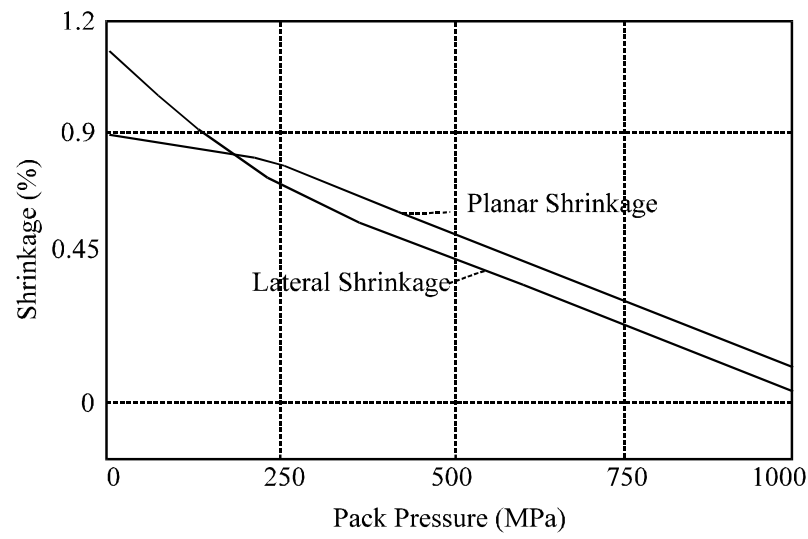

Fig. 17: Variation of Shrinkage Versus Packing Pressure: Gate Freezing Occurred at $\mathrm{t}_{\mathrm{fre}}=3 \mathrm{sec}$

\section{Procedure of ANOVA}

Designing the Experiments: The foregoing results have been obtained through changing one factor while other factors are constant. In this research, a DOE/Taguchi approach is used to study the effects of multiple variables simultaneously. Five factors including critical relaxation time, melt temperature, mold temperature, pack pressure and gate freezing time will be investigated and their percentage of influence will be specified through ANOVA. Based on known 


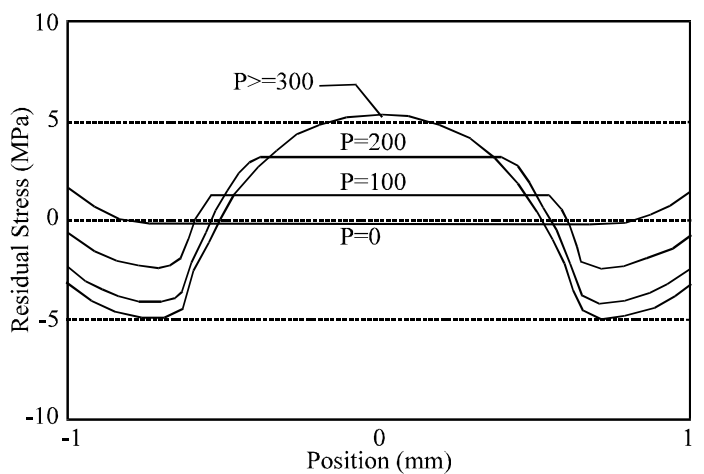

Fig. 18: Residual Stress Distribution curves for Different Packing Pressures: Gate Freezing Occurred at $\mathrm{t}_{\mathrm{fre}}=3 \mathrm{sec}$

variation of shrinkage with respect to different factors, which usually seems nonlinear from resultant curves, each factor is considered to have three levels. So there are five three-level factors and a L-18 orthogonal array must be selected to run the experiments. Table 1 shows the factors and their levels and the layout for the selected array is presented in Table 2.

Table 1: Influential Factors on Shrinkage and Their Selected Values

\begin{tabular}{llll}
\hline Factors & Level 1 & Level 2 & Level 3 \\
\hline A:log CRT & -5 & -2 & 0 \\
B:Melt Temp $\left({ }^{\circ} \mathrm{C}\right)$ & 220 & 290 & 360 \\
C:Mold Temp ( $\left.{ }^{\circ} \mathrm{C}\right)$ & 60 & 85 & 110 \\
D:Pack (bar) & 200 & 450 & 700 \\
E:GFT & $60 \%$ & $80 \%$ & $100 \%=\mathrm{CST}^{*}$ \\
\hline
\end{tabular}

*CST stands for complete solidification time

Table 2: A Standard L-18 (18 Experiment Runs) Array for Five Three-level Factors

\begin{tabular}{lllllllll}
\hline & 1 & 2 & 3 & 4 & 5 & 6 & 7 & 8 \\
\hline Trial 1 & 0 & 1 & 1 & 1 & 1 & 1 & 0 & 0 \\
Trial 2 & 0 & 1 & 2 & 2 & 2 & 2 & 0 & 0 \\
Trial 3 & 0 & 1 & 3 & 3 & 3 & 3 & 0 & 0 \\
Trial 4 & 0 & 2 & 1 & 1 & 2 & 2 & 0 & 0 \\
Trial 5 & 0 & 2 & 2 & 2 & 3 & 3 & 0 & 0 \\
Trial 6 & 0 & 2 & 3 & 3 & 1 & 1 & 0 & 0 \\
Trial 7 & 0 & 3 & 1 & 2 & 1 & 3 & 0 & 0 \\
Trial 8 & 0 & 3 & 2 & 3 & 2 & 1 & 0 & 0 \\
Trial 9 & 0 & 3 & 3 & 1 & 3 & 2 & 0 & 0 \\
Trial 10 & 0 & 1 & 1 & 3 & 3 & 2 & 0 & 0 \\
Trial 11 & 0 & 1 & 2 & 1 & 1 & 3 & 0 & 0 \\
Trial 12 & 0 & 1 & 3 & 2 & 2 & 1 & 0 & 0 \\
Trial 13 & 0 & 2 & 1 & 2 & 3 & 1 & 0 & 0 \\
Trial 14 & 0 & 2 & 2 & 3 & 1 & 2 & 0 & 0 \\
Trial 15 & 0 & 2 & 3 & 1 & 2 & 3 & 0 & 0 \\
Trial 16 & 0 & 3 & 1 & 3 & 2 & 3 & 0 & 0 \\
Trial 17 & 0 & 3 & 2 & 1 & 3 & 1 & 0 & 0 \\
Trial 18 & 0 & 3 & 3 & 2 & 1 & 2 & 0 & 0 \\
\hline
\end{tabular}

The experiments are carried out using the simulation code and the planar and thickness shrinkages obtained from each experiment are shown in Table 3.
Table 3: The Values of Planar and Thickness Shrinkages (P. Sh and T. Sh) in all 18 Trials

\begin{tabular}{lll}
\hline Trial No. & P. Sh $(\%)$ & T.Sh $(\%)$ \\
\hline 1 & 0.826 & 0.884 \\
2 & 0.699 & 0.671 \\
3 & 0.474 & 0.489 \\
4 & 0.598 & 0.328 \\
5 & 0.395 & 0.175 \\
6 & 0.845 & 1.198 \\
7 & 0.731 & 0.445 \\
8 & 0.664 & 0.684 \\
9 & 0.431 & 0.173 \\
10 & 0.51 & 0.542 \\
11 & 0.806 & 0.601 \\
12 & 0.781 & 1.04 \\
13 & 0.461 & 0.365 \\
14 & 0.808 & 0.798 \\
15 & 0.572 & 0.21 \\
16 & 0.553 & 0.41 \\
17 & 0.491 & 0.327 \\
18 & 0.788 & 0.644 \\
\hline
\end{tabular}

Analyzing the Results: At first, considering planar shrinkage as a target function, the results are analyzed. The main effects table, which presents the mean value of shrinkage for each factor at all levels, is shown in Table 4. Having performed the analysis of means (ANOM), the procedure of ANOVA is used to calculate the percentage influence of each factor to the target function, i.e. planar shrinkage. From results of ANOVA shown in Table 5 as was expected the packing pressure is the most influential factor $(86.292 \%)$ while the mold temperature has the least influence $(0.23 \%)$ on planar shrinkage.

Table 4: The Mean Value of Planar Shrinkage for Each Factor at All Levels

\begin{tabular}{llll}
\hline Factors & Level 1 & Level 2 & Level 3 \\
\hline A:CRT & 0.682 & 0.613 & 0.609 \\
B:Melt Temp. & 0.613 & 0.643 & 0.648 \\
C:Mold Temp. & 0.62 & 0.642 & 0.642 \\
D:Pack & 0.8 & 0.644 & 0.46 \\
E:GFT & 0.678 & 0.638 & 0.588 \\
\hline
\end{tabular}

Predicted optimum combination of factors is shown in Table 6. It also presents each factor contribution to the target function. The predicted result at optimum combination and confidence interval (CI) are calculated from the following relations:

$\mathrm{Y}_{\text {opt }}=\overline{\mathrm{T}}+\left(\overline{\mathrm{A}}_{\mathrm{i}}-\overline{\mathrm{T}}\right)+\left(\overline{\mathrm{B}}_{\mathrm{j}}-\overline{\mathrm{T}}\right)+\left(\overline{\mathrm{C}}_{\mathrm{k}}-\overline{\mathrm{T}}\right)$

C.I. $=\sqrt{\frac{F\left(1, n_{2}\right) \times V_{e}}{N_{e}}}$ 
Table 5: ANOVA Table for Planar Shrinkage

\begin{tabular}{lllllll}
\hline Factors & DOF & Sum of squares & Variance & F- ratio & Pure sum & Percent P\% \\
\hline A:CRT & 2 & 0.02 & 0.01 & 21.058 & 0.019 & 4.814 \\
B:Melt Temp & 2 & 0.004 & 0.002 & 4.576 & 0.003 & 0.858 \\
C:Mold Temp & 2 & 0.001 & 0 & 1.958 & 0 & 0.23 \\
C:Pack & 2 & 0.348 & 0.174 & 360.522 & 0.347 & 86.292 \\
E:GFT & 2 & 0.024 & 0.012 & 25.013 & 0.023 & 5.763 \\
Error Term & 7 & 0.002 & 0 & & & 2.043 \\
Total & 7 & 0.402 & & & & $100 \%$ \\
\hline
\end{tabular}

Table 6: Optimum Condition for Planar Shrinkage

\begin{tabular}{llll}
\hline Factors & Value & Level & Contribution \\
\hline A:CRT & 0 & 3 & -0.026 \\
B:Melt Temp & 220 & 1 & -0.023 \\
C:Mold Temp & 60 & 1 & -0.015 \\
D:Pack & 700 & 3 & -0.175 \\
E:GFT & $100 \%$ & 3 & -0.047 \\
Total contribution of factors & -0.286 \\
Grand average of performance & 0.635 \\
Expected result at optimum & 0.349 \\
\hline
\end{tabular}

In the first equation, $\overline{\mathrm{T}}$ is the grand average of performance and $\overline{x_{i}}$ denotes the average effect of factor $X$ at its optimum level. In the second equation, $\mathrm{F}\left(1, \mathrm{f}_{\mathrm{e}}\right)$ is the $F$ value from the $F$ Table [14] for a given confidence level and Ve denotes the variance of the error term and $\mathrm{N}_{\mathrm{e}}$ is calculated by:

$\mathrm{N}_{\mathrm{e}}$ =total DOFs / (1 + DOF of all factors Included in the study)

Now, the predicted optimum value and confidence interval for $90 \%$ confidence level are obtained from eq. 33 ,

$$
\mathrm{OCF}=\left[\begin{array}{lllll}
\mathrm{A} 3 & \mathrm{~B} 1 & \mathrm{C} 1 & \mathrm{D} 3 & \mathrm{E} 3
\end{array}\right]
$$

$\mathrm{Y}_{\mathrm{opt}}=0.349$

C.I. $=0.026$

Therefore, the expected result at optimum condition must be in the following range:

\section{$0.323 \leq$ ERatOpt $\leq 0.375$}

Furthermore, Each factor contribution to the Grand Average of Performance (GAP) is represented in the form of a bar diagram in Fig. 19. It shows that the average of performance is improved about $50 \%$ by equating all factors to their optimum values.

The same procedure is used to analyze the results for thickness shrinkage as a target function. The results of ANOM and ANOVA are presented in Table 7 and 8, respectively.

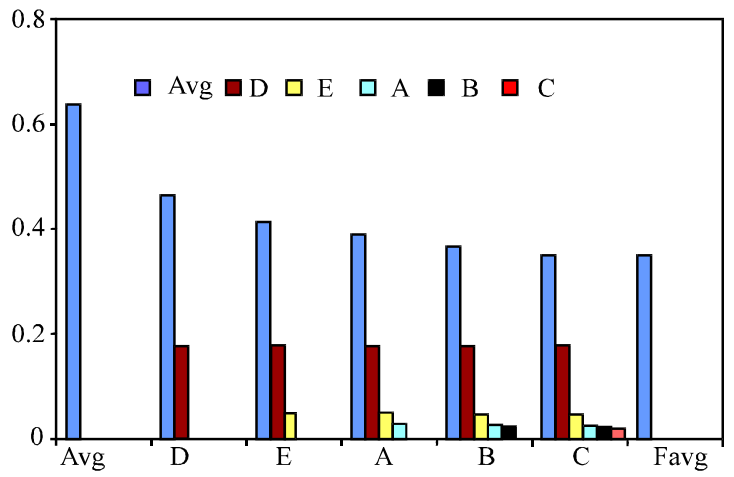

Fig. 19: Bar Diagram of Each Factor Contribution to the GAP

From Table 8, the packing pressure is again the most influential (35.214\%) while the melt temperature has the least influence $(2.742 \%)$ on thickness shrinkage.

Table 7: The Mean Value of Thickness Shrinkage for Each Factor at All Levels

\begin{tabular}{llll}
\hline Factors & Level 1 & Level 2 & Level 3 \\
\hline A:CRT & 0.704 & 0.512 & 0.447 \\
B:Melt Temp. & 0.495 & 0.542 & 0.625 \\
C:Mold Temp. & 0.42 & 0.556 & 0.686 \\
D:Pack & 0.761 & 0.557 & 0.345 \\
E:GFT & 0.749 & 0.526 & 0.388 \\
\hline
\end{tabular}

Table 9 shows the predicted Optimum Combinations of Factors (OCF), each factor contribution to the target function and the predicted value at optimum condition. From Table 9 and Table 6 it can be observed that both Optimum combinations are the same as each other. The predicted optimum value and confidence interval for 90\% confidence level are calculated by eq. 33:

$\mathrm{OCF}=\left[\begin{array}{lllll}\mathrm{A} 3 & \mathrm{~B} 1 & \mathrm{C} 1 & \mathrm{D} 3 & \mathrm{E} 3\end{array}\right]$

$\mathrm{Y}_{\mathrm{opt}}=-0.125$

C.I. $=0.11$

And the permissible limit for the result of optimum experiment is:

$-0.235 \leq$ ERatOpt $\leq-0.015$ 
Table 8: ANOVA Table for Planar Shrinkage

\begin{tabular}{lclllll}
\hline Factors & DOF & Sum of Squares & Variance & F-ratio & Pure Sum & Percent P\% \\
\hline A: C.R.T & 2 & 0.214 & 0.107 & 17.27 & 0.202 & 14.025 \\
B: Melt Temp & 2 & 0.051 & 0.025 & 4.18 & 0.039 & 2.742 \\
C: Mold Temp & 2 & 0.212 & 0.106 & 17.113 & 0.2 & 13.89 \\
D: Pack & 2 & 0.52 & 0.26 & 41.849 & 0.508 & 35.214 \\
E: GFT & 2 & 0.399 & 0.199 & 32.088 & 0.386 & 26.799 \\
& & & & & & 7.33 \\
Error Term & 7 & 0.042 & 0.006 & & & $100 \%$ \\
Total: & 17 & 1.442 & & & & \\
\end{tabular}

Table 9:Optimum Condition for Thickness Shrinkage

\begin{tabular}{llll}
\hline Factors & Value & Level & Contribution \\
\hline A:CRT & 0 & 3 & -0.108 \\
B:Melt Temp & 220 & 1 & -0.159 \\
C:Mold Temp & 60 & 1 & -0.135 \\
D:Pack & 700 & 3 & -0.21 \\
E:GFT & $100 \%$ & 3 & -0.167 \\
Total contribution of factors & & -0.68 \\
\multicolumn{2}{l}{ Grand average of performance } & 0.554 \\
\multicolumn{2}{l}{ Expected result at optimum } & -0.125 \\
\hline
\end{tabular}

Confirming the Predicted Results: Having performed the analysis of results, the predicted optimum result must be verified through carrying out experiments at optimum combination of factors. If the result of optimum experiment is within the permissible limit the predicted result will be verified and otherwise, the DOE experiments must be redesigned and rerun considering interactions between factors.

Running the experiments at optimum combination for both shrinkages results in

Planar Shrinkage $(\%)=0.369$

Thickness Shrinkage $(\%)=-0.056$

Both values are within the permissible limit and therefore, the predicted results for both shrinkages are confirmed. Here, confirmation means that, for $90 \% \mathrm{CL}$, there is no need to repeat the procedure of DOE with counting for interactions between factors. In other words, if an experiment design considering factor interactions is performed, it can be predicted that these interactions have such a small effect-from test of significance for $90 \%$ CL--that can be pooled from ANOVA Table.

\section{CONCLUSION}

A simple flat model has been used to investigate the effects of different process conditions on shrinkage and residual stresses. Material was assumed to be thermorheologically simple with WLF shift function. To study the effects of packing pressure, the reference strain concept was used and using this concept, the linear constitutive equation was expressed with respect to initial cavity dimensions. In this regard, a phase transition criterion was used to specify the phase of the material at any instant. Then, heat transfer and constitutive equations has been solved by numerical methods and based on these solutions a simulation code has been developed.

A parametric study has been performed through running the simulation code for a sample polymer. The results showed that the packing pressure highly influences planar and thickness shrinkages, while the effect of initial melt temperature is very small. Mold temperature has very small effect on planar shrinkage, while its effect on thickness shrinkage is considerable. Moreover, Gate freezing before complete solidification increases both shrinkages in constant packing pressures. The foregoing simulation results have been obtained by changing one factor at a time. To study the effects of different factors simultaneously, a Taguchi approach was implemented. Based on this approach, different tests (simulations) have been carried out using a standard L-18 orthogonal array. The ANOVA tables presented that the order of significance, changing factors simultaneously, is the same as what was acquired from simulation, changing one factor at a time. Finally, the predicted results were confirmed. This confirmation means that the experiments need not be repeated with considering interactions between factors. In fact, if experiments are rerun counting for interactions between factors, the test of significance will result in pooling these interactions from ANOVA Table.

\section{REFERENCES}

1. Choi, D.S. and Y.T. Im, 1999. Prediction of shrinkage and warpage in consideration of residual stress in integrated simulation of injection molding. Composite Structures, 47: 655-665.

2. Bushko, W.C. and V.K. Stokes, 1995. Solidification of thermoviscoelastic melts Part I: Formulation of model problem. Polym. Eng. Sci, 35: 351-364. 
3. Santhanam, N., 1992. Analysis of residual stresses and post-molding deformation in injection-molded components, Ph.D Thesis, Cornell University, Ithaca, USA.

4. Kabanemi, K.K. and M.J. Crochet, 1992. Thermoviscoelastic calculation of residual stresses and residual shapes of injection-molded parts. Polymer Process, 7: 60-70.

5. Liu, S.J., 1996. Modeling and simulation of thermally induced stress and warpage in injection molded thermoplastics. Polym. Eng. Sci., 36: 807-818.

6. Kabanemi, K.K., H. Vaillancourt, H. Wang and G. Salloum, 1998. Residual stresses, shrinkage and warpage of complex injection molded products: Numerical simulation and experimental validation. Polym. Eng. Sci., 38: 21-37.

7. Zoetelief, W.F., L.F.A. Douven and A.J. Housz, 1996. Residual thermal stresses in injection molded products. Polym. Eng. Sci., 36: 1886-1896.

8. LeGrand, D.G., 1985. Transient stresses during extrusion and injection molding of thermoplastics. GE Corporate Research and Development Technical Information Series, Report No. 85CRD127.
9. Huang, M.C. and C.C. Tai, 2001. The effective factors in the warpage problem of an injectionmolded part with a thin shell feature. Materials Processing Technology, 110: 1-9.

10. Chang, T.C., 2001. Shrinkage behavior and optimization of injection-molded parts studied by the Taguchi method. Polym. Eng. Sci., 41: 703710 .

11. Ferry, J.D., 1980. Viscoelastic Properties of Polymers, $3^{\text {rd }}$ Edn. Wiley-Interscience Publication.

12. Osswald, T.A. and G. Menges, 2003. Materials Science of Polymers for Engineers. $2^{\text {nd }}$ Edn. Hanser Publishers.

13. Bushko, W.C. and V.K. Stokes, 1995. Solidification of thermoviscoelastic melts Part II: Effects of processing conditions on shrinkage and residual stresses. Polym. Eng. Sci., 35: 365-383

14. Roy, R.K., 2001. Design of Experiments Using the Taguchi Approach. Wiley-Interscience Publication. 